\title{
GPR40: A therapeutic target for mediating insulin secretion (Review)
}

\author{
XIAO-TAO FENG ${ }^{1}$, JING LENG $^{1}$, ZHEN XIE $^{3}$, SHUANG-LEI LI $^{2}$, WEI ZHAO ${ }^{2}$ and QIAN-LI TANG ${ }^{1}$ \\ ${ }^{1}$ Guangxi Scientific Experimental Center of Traditional Chinese Medicine, ${ }^{2}$ Department of Endocrinology, \\ First Affiliated Hospital and ${ }^{3}$ Department of Pharmaceutical Analysis, Faculty of Pharmacy, \\ Guangxi University of Chinese Medicine, Nanning, P.R. China
}

Received June 11, 2012; Accepted August 26, 2012

DOI: $10.3892 /$ ijmm.2012.1142

\begin{abstract}
G-protein-coupled receptor 40 (GPR40), known as free fatty acid receptor 1 , is mainly expressed in pancreatic $\beta$-cells and activated by medium- and long-chain fatty acids. Increasing evidence indicates that the activation of GPR40 in cells causes insulin secretion, and GPR40 has become an attractive therapeutic target for type 2 diabetes. Recently, certain novel GPR40 agonists have been identified that regulate glucose-stimulated insulin secretion, leading to the development of new drugs for the treatment of type 2 diabetes. In this review, we focus on progress in the physiological role of GPR40 and potential drugs targeting GPR40 over the past decade.
\end{abstract}

\section{Contents}

1. Introduction

2. Gene and protein information for GPR40

3. Ligands

4. Physiological role of GPR40 in mediating insulin secretion

5. Emerging potential drugs targeting GPR40 for the regulation of insulin secretion

6. Conclusion and perspectives

\section{Introduction}

Type 2 diabetes is one of the crucial health problems worldwide, and its prevalence is rising dramatically $(1,2)$. In

Correspondence to: Wei Zhao, Department of Endocrinology, First Affiliated Hospital, Guangxi University of Chinese Medicine, 89-9 Dongge Road, Nanning 530023, P.R. China

E-mail: weizhnn@163.com

Qian-Li Tang, Guangxi Scientific Experimental Center of Traditional Chinese Medicine, Guangxi University of Chinese Medicine, 179 East Mingxiu Road, Nanning 530001, P.R. China E-mail: htmgx@163.com

Key words: type 2 diabetes, free fatty acids, G-protein-coupled receptor, pancreatic $\beta$-cells, insulinotropic reagent addition to insulin resistance, pancreatic $\beta$-cell dysfunction typically characterized by progressive decreases in glucosestimulated insulin secretion (GSIS), is another hallmark of type 2 diabetes. As is well known, plasma glucose is a leading adaptor in mediating insulin secretion. Elevated blood glucose levels cause glucose to diffuse into $\beta$-cells through the non-insulin-dependent glucose transporter-2 (Glut2) and then glucose metabolism results in the production of adenosine triphosphate (ATP). Increased ATP levels, particularly a rise in the ratio of ATP/adenosine diphosphate (ADP), lead to the closure of $\mathrm{K}^{+}$-ATP channels and subsequent plasma membrane depolarization. This opens voltage-dependent $\mathrm{Ca}^{2+}$ channels and causes subsequent $\mathrm{Ca}^{2+}$ influx, and increased cytoplasmic free $\mathrm{Ca}^{2+}$ levels prompt insulin granule exocytosis, thus triggering insulin secretion (3) (Fig. 1).

Additionally, free fatty acids (FFAs) are not only essential dietary nutrients, but play a crucial role in the modulation of insulin secretion (4-6). It is believed that prolonged exposure to elevated FFAs results in impaired insulin secretion involving lipotoxicity which exerts the deleterious effects of lipid accumulation on $\beta$-cell secretory function by inhibiting insulin biosynthesis $(7,8)$, promoting programmed cell death (9) and inducing reactive oxidant species (ROS) generation and inflammatory reaction $(10,11)$. However, recent evidence indicates that not all FFAs inhibit insulin secretion. The long-term in vitro treatment of INS-1 rat pancreatic $\beta$-cells by polyunsaturated $\alpha$-linolenic acid does not reduce insulin secretion and saturated palmitic acid-induced suppression of basal insulin secretion and GSIS is attenuated by $\alpha$-linolenic acid (12). On the contrary, FFAs acutely enhance basal insulin secretion and GSIS, and the molecular mechanisms involve the surface receptors of pancreatic $\beta$-cells. Over the past decades, a series of receptors have been identified for FFAs, such as the nuclear receptors, peroxisome proliferator-activated receptors (PPARs), fatty acid-binding proteins (FABPs) and G-protein-coupled receptors (GPRs), a large family of cell surface receptors $(13,14)$. Moreover, cell surface receptors have been proven to play a key role in FFA biological processes, which suggests that FFAs do not need to enter into the cells to elicit their effects. Recently, GPRs have been successfully identified as multiple cell surface receptors for FFAs, also known as FFA receptors (FFARs). Among these, GPR41 and GPR43, known as FFAR3 and FFAR2, respectively, are 
activated by short-chain fatty acids, such as formate, acetate, propionate and butyrate (15), while GPR40 and GPR 120 by medium- and long-chain ones, such as palmitate, palmitoleate and oleate (16,17). GPR41 is expressed in adipose tissue and the gastrointestinal tract, and short-chain FFAs induce leptin secretion from adipocytes by stimulating GPR41, suggesting that GPR41 regulates energy homeostasis (18). GPR43 has been detected in immune cells, adipocytes and the gastrointestinal tract, and contributes to inflammatory responses and metabolic homeostasis (19-21). GPR120, primarily expressed in the intestine and macrophages, promotes glucagon-like peptide-1 (GLP-1) secretion from the intestine and represses macrophage-induced inflammation $(22,23)$. GPR 40 , namely FFAR1, is executively expressed in pancreatic $\beta$-cells and mediates insulin secretion upon medium- and long-chain FFA stimulation $(16,24)$. Type 2 diabetes islets have a lower GPR40 expression with impaired insulin secretion (25) and GPR40 knockout leads to decreases in both glucose- and argininestimulated insulin secretion in vivo without changes in insulin sensitivity (26). The overexpression of GPR40 in pancreatic $\beta$-cells augments GSIS and improves glucose tolerance in normal and diabetic mice (27), and the GPR40 agonist also displays the same effects in rodents (28). Therefore, GPR40 has received considerable attention as a potential therapeutic target for type 2 diabetes, and a series of novel agonists for GPR40 have been found, leading to the development of new drugs for type 2 diabetes $(29,30)$.

\section{Gene and protein information for GPR40}

In addition to being expressed in pancreatic $\beta$-cells in a range of species including mice, rats and humans $(6,31,32)$, GPR40 is expressed at very low levels in all other tissues $(16,33)$. The GPR40 gene is located on human chromosome 19q13.1, and shares approximately $30-40 \%$ identity with GPR41 and GPR43 (14). The mouse gene is composed of a 24-bp noncoding exon, a 698-bp intron and a 4402-bp second exon, of which the intron is located between the 2 exons and is spliced out during RNA processing, and the second exon contains the full coding sequence. Three evolutionarily conserved sequences (HR1-HR3) are located upstream of the first exon. Among these, HR2 is a potent $\beta$-cell-specific enhancer and binds transcription factors, PDX1 and BETA2, and is thus responsible for regulating the transcriptional levels of the gene in $\beta$-cells $(34,35)$. GPR40 belongs to class A GPRs, showing a typical 7-transmembrane (TM) domain structure spanning $\alpha$-helices with 3 hydrophilic intracellular and 3 hydrophilic extracellular loops. The $\mathrm{N}$-terminus is located extracellularly while the C-terminus resides in the cytosol (36). Although the full protein information for GPR40 has not yet been revealed, its structure has been analyzed by computational modeling, site-directed mutagenesis and so on. GPR40 contains 2 sites (Thr215 and Ser298) bearing potential protein kinase C (PKC) phosphorylation and 2 putative $\mathrm{N}$-glycosylation ones (Asn155 and Asn165) (37). Additionally, the anchored sites of fatty acids are determined in amino residues Arg183, Asn244 and Arg258 located close to the extracellular domains of TM5, 6 and 7 when GPR40 is stimulated. In the resting state, the Arg183 and Arg258 residues consist of an ionic lock with 2 glutamate residues (Glu145 and Glu172) located in TM2. In the presence of ligands, however, the ionic lock is broken, and then Arg183 and Arg258 are anchored by fatty ligands (37-40). A recent study revealed that His137 directly refers to ligand recognition through the NH- $\pi$ interaction with GW9508, while His 86 does not interact with GW9508 in the NH- $\pi$ interaction (41). It has been proven that the Arg211His and Gly180Ser polymorphisms in the GPR 40 gene are strongly linked to receptor functionality and insulin secretion $(42,43)$.

\section{Ligands}

Three independent groups have reported that GPR40 is activated by medium- and long-chain FFAs in the micromolar concentration range (44-46), including saturated fatty acids and unsaturated fatty acids. The agonistic activity of the former is dependent on chain length from at least 10 carbon atoms (capric acid) to as many as 23 (tricosanoic acid), of which pentadecanoic acid (C15) and palmitic acid (C16) display the most potent agonistic activity, while capric acid (C10) demonstrates either weak or no activity. However, the latter, including a variety of monounsaturated fatty acids such as 9Z-palmitoleic acid (C16:1) and 9Z-oleic acid (C18:1) and polyunsaturated fatty acids such as 9Z,12Z-linoleic acid (C18:2) and 5,8,11-eicosatrienoic acid (C20:3), do not appear to be dependent on carbon chain length or the degree of saturation (44). Additionally, a series of synthetic agonists such as GW9508, AMG 837 and 3-substituted 3-(4-aryloxyaryl)propanoic acids have been recently reported (47-50). Several synthetic GPR40 antagonists have also been well described, including DC260126 and GW1100 (51-54).

\section{Physiological role of GPR40 in mediating insulin secretion}

Elevated plasma FFAs often co-exist with type 2 diabetes and obesity, and fatty acids play an important role in insulin secretory function of $\beta$-cells. In the absence of fatty acids, GSIS is impaired. On the contrary, an increase in blood FFA concentration augments GSIS (55). Contrary to the acute effects of FFAs, chronically elevated fatty acids have been strongly linked to reduced insulin secretion (56). However, it is not always true that all FFAs impair $\beta$-cell function; prolonged exposure to unsaturated FFAs, such as polyunsaturated $\alpha$-linolenic acid but not saturated palmitic acid protects $\beta$-cell function and augments GSIS (12). As a receptor of mediumand long-chain FFAs, GPR40 has been well documented to contribute to insulin secretion. GPR40 is highly expressed in human pancreatic $\beta$-cells, islet cell tumors and various pancreatic-derived cell lines, including INS-1E, MIN6, $\beta$-TC-3 and HIT-T15. Islets from type 2 diabetic patients chronically exposed to FFA have a lower GPR40 mRNA expression than those from non-diabetic multiorgan donors, following impaired insulin secretion $(25,57)$. Likewise, the deletion of GPR40 decreases GSIS in vivo in mice without affecting intracellular fuel metabolism in islets and insulin sensitivity $(26,58)$, and the islets from GPR40 knockout mice have a reduced capacity to release insulin in response to fatty acids $(26,59)$, which suggests that GPR40 is required for normal insulin secretion. The overexpression of GPR40, however, improves glucose tolerance with an increase in insulin secretion in normal and diabetic mice. Moreover, 


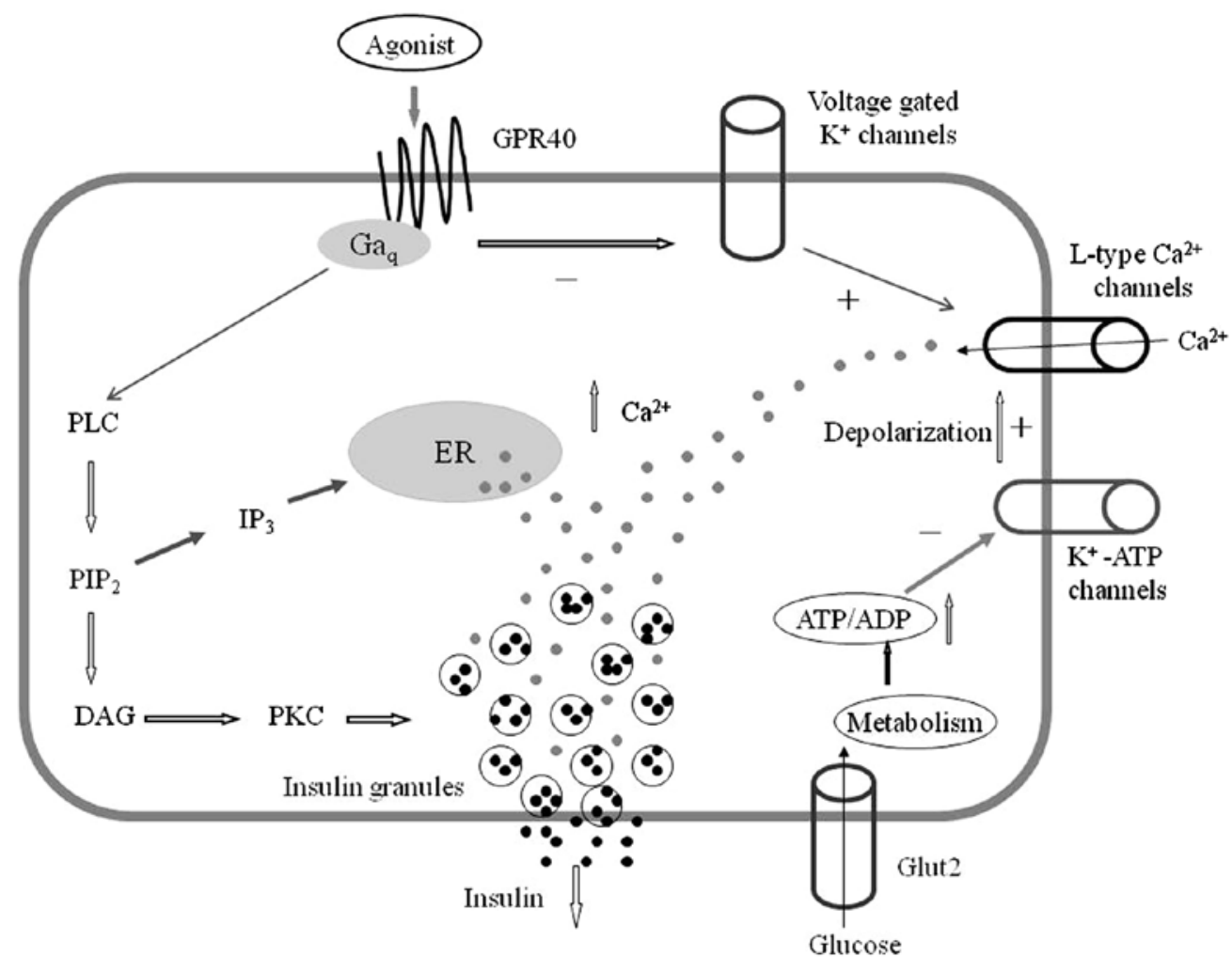

Figure 1. GPR40 signaling in pancreatic $\beta$-cells.

mice have been found to be resistant to high-fat diet-induced glucose intolerance, and isolated islets from mice potentiate enhanced insulin secretion in response to high glucose and resist the impairment of $\beta$-cells in insulin secretion against prolonged palmitate exposure (27).

Upon stimulation by agonists, GPR40 couples to the $\mathrm{Ca}^{2+}$-mobilizing $\mathrm{G}$ protein, $\mathrm{Ga}_{\mathrm{q}}$ (44). This results in phospholipase C (PLC) activation which promotes plasma membrane phosphatidylinositol-4,5-bisphosphate $\left(\mathrm{PIP}_{2}\right)$ to generate inositol-1,4,5-trisphosphate $\left(\mathrm{IP}_{3}\right)$ and diacylglycerol (DAG). Then, $\mathrm{IP}_{3}$ transfers into the endoplasmic reticulum (ER), thus leading to the release of stored $\mathrm{Ca}^{2+}$ from ER and subsequently increased cytoplasmic $\mathrm{Ca}^{2+}$ levels, while DAG potentiates insulin secretion by stimulating PKC $(9,16)$. GPR40 knockout contributes to the decrease in lyso-phosphatidylethanolamine species and absence in intracellular inositol phosphate levels in response to fatty acids and subsequent reduction in GSIS (26). The inhibition of PLC or L-type $\mathrm{Ca}^{2+}$ channels attenuates rises in GPR40-dependent $\mathrm{Ca}^{2+}$ levels and insulin secretion stimulated by fatty acids; the same effects are observed in GPR40 knockout $\beta$-cells (60-62). This process suggests that GPR40 mediates insulin secretion involving $\mathrm{Ca}^{2+}$ release from $\mathrm{ER}$ and influx via L-type $\mathrm{Ca}^{2+}$ channels. Moreover, linoleic acid reversibly reduces the voltage-gated $\mathrm{K}^{+}$current in rat $\beta$-cells through GPR40, while GPR40-specific small interfering RNA significantly reduce the decrease in $\mathrm{K}^{+}$current induced by linoleic acid. Taken together, these data indicate that activated GPR40 inhibits the opening of voltage-gated $\mathrm{K}^{+}$ channels, resulting in increased $\mathrm{Ca}^{2+}$ influx via L-type $\mathrm{Ca}^{2+}$ channels, and therefore enhancing the depolarization of the plasma membrane, thereby augmenting GSIS (63) (Fig. 1).

\section{Emerging potential drugs targeting GPR40 for the regulation of insulin secretion}

Due to tissue distribution, the pharmacological activation of GPR40 provides a novel target for the treatment of type 2 diabetes. Certain synthetic GPR40 agonists are very promising to become the drug for mediating insulin secretion. For example, GW9508, a small molecule agonist, activates GPR40 and stimulates GSIS in MIN6 cells, implicating a potential glucose-sensitive insulin secretagogue (64). A phenylpropanoic acid derivative named 3-\{2-fluoro-4-[(\{4'[(4-hyd roxy-1,1-dioxidotetrahydro-2H-thiopyran-4-yl) methoxy]-2',6'-dimethylbiphenyl-3-yl\}methyl)amino]phenyl\} propanoic acid has been shown to exhibit a robust plasma glucose-lowering effect and insulinotropic action during an oral glucose tolerance test in rats with impaired glucose tolerance (65). AMG 837 is a potent GPR40 agonist with a superior pharmacokinetic profile, improving glucose intolerance and promoting GSIS in rodents $(28,66)$. Although thiazolidinediones including pioglitazone, the insulin sensitizers, are proven to activate GPR40 and reverse palmitate-induced $\beta$-cell dysfunction $(67,68)$, the adverse effects such as heart problems and bone fractures have already been reported $(69,70)$. Recently, Zhou et al (71) discovered a series of thiazolidinediones (TZDs) as potent GPR40 agonists by systematic structure-activity relationship studies of a screening. Among these, compound $\mathrm{C}$ demonstrated an acute mechanism-based glucose lowering in an intraperitoneal glucose tolerance test (IPGTT) in lean mice, while no effects were observed in GPR40 knockout mice. However, it is necessary to determine whether compound $\mathrm{C}$ has the same adverse effects. 


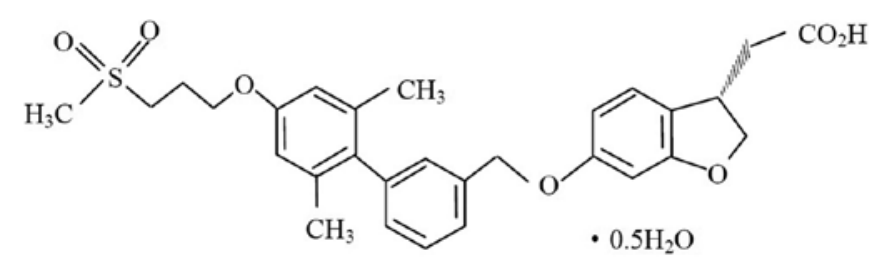

Figure 2. Chemical structure of TAK-875 (74).

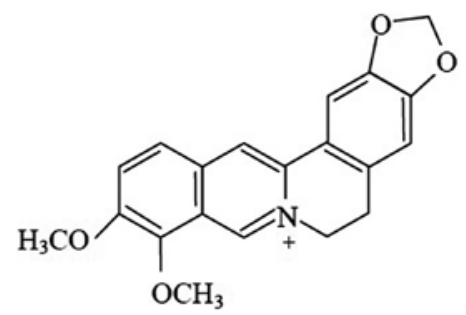

Figure 3. Chemical structure of berberine.
TAK-875, a GPR40-selective agonist (Fig. 2), enhances insulin secretion in a glucose-dependent manner in both isolated rat and human islets, which correlates with the elevation of intracellular inositol monophosphate and $\mathrm{Ca}^{2+}$ concentration, similar to that produced by GLP-1 $(72,73)$, thus minimizing the risk of hypoglycemia and representing a therapeutically useful feature. The oral administration of TAK-875 significantly improves both fasting hyperglycemia and glucose tolerance and augments GSIS in type 2 diabetic rats with no evidence of $\beta$-cell toxicity, showing promising pharmacokinetic profiles (73,74). Further research has revealed that TAK-875 is well tolerated in healthy volunteers and has pharmacokinetic characteristics suitable for a once daily regimen, and pharmacodynamic data have shown that TAK-875 has a low risk of hypoglycemia (75). At present, the agonist has been studied in clinical trials $(76,77)$, including a phase II, multicentre, randomized, double-blind, parallel group study. After treatment, TAK-875 led to reductions in blood glucose levels and HbA1c and an increase in insulin levels. Moreover, no episode of hypoglycemia was observed despite the significant reduction in plasma glucose levels. These findings indicate that the GPR40 agonist, TAK-875, is a glucose-dependent insulinotropic reagent and a promising clinical drug for the treatment of type 2 diabetes.

In China, a number of Chinese herbs have been shown to possess antidiabetic activities with few adverse effects (78), including Coptis chinensis, Astragalus membranaceus and Lonicera japonica $(79,80)$; however, the mechanisms involved remain unclear. Berberine, a botanical alkaloid (Fig. 3) extracted from Coptis chinensis Franch., has been used to treat type 2 diabetes in clinical practice. Although certain gastrointestinal complaints from berberine treatment, including slight constipation appear to be associated with the use of high doses, the tolerability is high for low doses (81). Berberine performs a series of pharmacological functions, including anti-inflammation, ameliorating insulin resistance and has a protective effect on $\beta$-cell lipoapoptosis $(82,83)$. It is not only an insulin sensitizer via enhancing glucose metabolism in insulin-sensitive tissues, but also an insulinotropic reagent. Previous studies have revealed that berberine stimulates glucose-dependent insulin secretion from rat pancreatic $\beta$-cells and exhibits a dose-dependent increase in calcium mobilization in a GPR40-overexpressed cell line, similar to oleic acid, a GPR40 agonist $(84,85)$. Therefore, it is possible that berberine is a novel agonist of GPR40. Additionally, Rehmanniae radix, Ginseng radix and Scutellariae radix have also been shown to have the potential to improve GSIS $(86,87)$.

\section{Conclusion and perspectives}

GPR40 is no doubt a novel therapeutic target for type 2 diabetes involving mediating insulin secretion, and a series of agonists for GPR40 have developed. However, further studies are warranted to determined the safety, tolerability, pharmacokinetic and pharmacodynamic properties. At present, a promising clinical drug targeting GPR40 is TAK-875, which is currently undergoing phase II, multicentre, randomized, double-blind, placebo-controlled trials. However, adverse effects including long-term reaction are not yet clear. GPR40 is also expressed in enteroendocrine and glial cells, and the ligands display toxic activity (88-90). Therefore, it is necessary to confirm whether TAK-875 affects these tissues. Additionally, Chinese medicine has been used to treat diabetes for thousands of years in clinical practice with few side-effects, and has become popular complementary and alternative medicine. A number of Chinese herbs have been proven to protect pancreatic $\beta$-cell function and to regulate insulin secretion. It is worthwhile to screen insulinotropic reagents from Chinese herbs and to develop GPR40 agonists. This may lead to a reduction in research funds and time.

\section{Acknowledgements}

This study was supported by the National Natural Science Foundation of China (no. 81202677) and Guangxi Natural Science Foundation (no. 2012GXNSFBA053103).

\section{References}

1. Yang W, Lu J, Weng J, et al: Prevalence of diabetes among men and women in China. N Engl J Med 362: 1090-1101, 2010.

2. Davis TM, Peters KE, Bruce DG and Davis WA: Prevalence, incidence and prognosis of hepatobiliary disease in communitybased patients with type 2 diabetes: the Fremantle Diabetes Study. J Clin Endocrinol Metab 97: 1581-1588, 2012.

3. Henquin JC: Triggering and amplifying pathways of regulation of insulin secretion by glucose. Diabetes 49: 1751-1760, 2000.

4. Sako Y and Grill V: A 48-hour lipid infusion in the rat timedependently inhibits glucose-induced insulin secretion and $\mathrm{B}$ cell oxidation through a process likely coupled to fatty acid oxidation. Endocrinology 127: 1580-1589, 1990.

5. Ayvaz G, Balos Törüner F, Karakoç A, et al: Acute and chronic effects of different concentrations of free fatty acids on the insulin secreting function of islets. Diabetes Metab 28: 3S7-3S12, 2002.

6. Schmidt J, Liebscher K, Merten N, et al: Conjugated linoleic acids mediate insulin release through islet $\mathrm{G}$ protein-coupled receptor FFA1/GPR40. J Biol Chem 286: 11890-11894, 2011.

7. Kashyap S, Belfort R, Gastaldelli A, et al: A sustained increase in plasma free fatty acids impairs insulin secretion in nondiabetic subjects genetically predisposed to develop type 2 diabetes. Diabetes 52: 2461-2474, 2003. 
8. Ritz-Laser B, Meda P, Constant I, et al: Glucose-induced preproinsulin gene expression is inhibited by the free fatty acid palmitate. Endocrinology 140: 4005-4014, 1999.

9. Gwiazda KS, Yang TL, Lin Y and Johnson JD: Effects of palmitate on ER and cytosolic $\mathrm{Ca}^{2+}$ homeostasis in $\beta$-cells. Am J Physiol Endocrinol Metab 296: E690-E701, 2009.

10. Lai E, Bikopoulos G, Wheeler MB, et al: Differential activation of ER stress and apoptosis in response to chronically elevated free fatty acids in pancreatic beta-cells. Am J Physiol Endocrinol Metab 294: E540-E550, 2008.

11. Böni-Schnetzler M, Boller S, Debray S, et al: Free fatty acids induce a proinflammatory response in islets via the abundantly expressed interleukin-1 receptor I. Endocrinology 150: 5218-5229, 2009.

12. Tuo Y, Feng DD, Wang DF, et al: Long-term in vitro treatment of INS-1 rat pancreatic $\beta$-cells by unsaturated free fatty acids protects cells against gluco- and lipotoxicities via activation of GPR40 receptors. Clin Exp Pharmacol Physiol 39: 423-428, 2012.

13. Chawla A, Repa JJ, Evans RM and Mangelsdorf DJ: Nuclear receptors and lipid physiology: opening the X-files. Science 294: $1866-1870,2001$

14. Sawzdargo M, George SR, Nguyen T, et al: A cluster of four novel human $\mathrm{G}$ protein-coupled receptor genes occurring in close proximity to CD22 gene on chromosome 19q13.1. Biochem Biophys Res Commun 239: 543-547, 1997.

15. Brown AJ, Goldsworthy SM, Barnes AA, et al: The Orphan G protein-coupled receptors GPR41 and GPR43 are activated by propionate and other short chain carboxylic acids. J Biol Chem 278: 11312-11319, 2003.

16. Schnell S, Schaefer M and Schofl C: Free fatty acids increase cytosolic free calcium and stimulate insulin secretion from beta-cells through activation of GPR40. Mol Cell Endocrinol 263: 173-180, 2007.

17. Miyauchi S, Hirasawa A, Ichimura A, et al: New frontiers in gut nutrient sensor research: free fatty acid sensing in the gastrointestinal tract. J Pharmacol Sci 112: 19-24, 2010.

18. Xiong Y, Miyamoto N, Shibata K, et al: Short-chain fatty acids stimulate leptin production in adipocytes through the G protein-coupled receptor GPR41. Proc Natl Acad Sci USA 101: 1045-1050, 2004.

19. Le Poul E, Loison C, Struyf S, et al: Functional characterization of human receptors for short chain fatty acids and their role in polymorphonuclear cell activation. J Biol Chem 278 : 25481-25489, 2003

20. Ge H, Li X, Weiszmann J, et al: Activation of G proteincoupled receptor 43 in adipocytes leads to inhibition of lipolysis and suppression of plasma free fatty acids. Endocrinology 149: 4519-4526, 2008.

21. Maslowski KM, Vieira AT, Ng A, et al: Regulation of inflammatory responses by gut microbiota and chemoattractant receptor GPR43. Nature 461: 1282-1286, 2009.

22. Hirasawa A, Tsumaya K, Awaji T, et al: Free fatty acids regulate gut incretin glucagon-like peptide-1 secretion through GPR120. Nat Med 11: 90-94, 2005

23. Oh DY, Talukdar S, Bae EJ, et al: GPR120 is an omega-3 fatty acid receptor mediating potent anti-inflammatory and insulinsensitizing effects. Cell 142: 687-698, 2010.

24. Kebede M, Alquier T, Latour MG, et al: The fatty acid receptor GPR40 plays a role in insulin secretion in vivo after high-fat feeding. Diabetes 57: 2432-2437, 2008.

25. Del Guerra S, Bugliani M, D'Aleo V, et al: G-protein-coupled receptor 40 (GPR40) expression and its regulation in human pancreatic islets: the role of type 2 diabetes and fatty acids. Nutr Metab Cardiovasc Dis 20: 22-25, 2010.

26. Alquier T, Peyot ML, Latour MG, et al: Deletion of GPR40 impairs glucose-induced insulin secretion in vivo in mice without affecting intracellular fuel metabolism in islets. Diabetes 58: 2607-2615, 2009.

27. Nagasumi K, Esaki R, Iwachidow K, et al: Overexpression of GPR40 in pancreatic beta-cells augments glucose-stimulated insulin secretion and improves glucose tolerance in normal and diabetic mice. Diabetes 58: 1067-1076, 2009.

28. Houze JB, Zhu L, Sun Y, et al: AMG 837: a potent, orally bioavailable GPR40 agonist. Bioorg Med Chem Lett 22: 1267-1270, 2012.

29. Negoro N, Sasaki S, Ito M, et al: Identification of fused-ring alkanoic acids with improved pharmacokinetic profiles that act as $\mathrm{G}$ protein-coupled receptor $40 /$ free fatty acid receptor 1 agonists. J Med Chem 55: 1538-1552, 2012.
30. Hara T, Hirasawa A, Ichimura A, et al: Free fatty acid receptors FFAR1 and GPR120 as novel therapeutic targets for metabolic disorders. J Pharm Sci 100: 3594-3601, 2011

31. Itoh Y and Hinuma S: GPR40, a free fatty acid receptor on pancreatic beta cells, regulates insulin secretion. Hepatol Res 33: 171-173, 2005.

32. Tomita T, Masuzaki H, Noguchi M, et al: GPR40 gene expression in human pancreas and insulinoma. Biochem Biophys Res Commun 338: 1788-1790, 2005.

33. Steneberg P, Rubins N, Bartoov-Shifman R, et al: The FFA receptor GPR40 links hyperinsulinemia, hepatic steatosis, and impaired glucose homeostasis in mouse. Cell Metab 1: 245-258, 2005.

34. Bartoov-Shifman R, Ridner G, Bahar K, et al: Regulation of the gene encoding GPR40, a fatty acid receptor expressed selectively in pancreatic beta cells. J Biol Chem 282: 23561-23571, 2007.

35. Ridner G, Bartoov-Shifman R, Zalogin T, et al: Regulation of the GPR40 locus: towards a molecular understanding. Biochem Soc Trans 36: 360-362, 2008.

36. Winzell MS and Ahrén B: G-protein-coupled receptor and islet function-implications for treatment type 2 diabetes. Pharmacol Ther 116: 437-448, 2007.

37. Stoddart LA, Smith NJ and Millgan G: International Union of Pharmacology. LXXI. Free fatty acid receptor FFA1, -2, and -3 : pharmacology and pathophysiological functions. Pharmacol Rev 60: 405-417, 2008.

38. Tikhonova IG, Sum CS, Neumann S, et al: Bidirectional, iterative approach to the structural delineation of the functional 'chemoprint' in GPR40 for agonist recognition. J Med Chem 50: 2981-2989, 2007.

39. Morgan NG and Dhayal S: G-protein coupled receptors mediating long chain fatty acid signalling in the pancreatic beta cell. Biochem Pharmacol 78: 1419-1427, 2009.

40. Sum CS, Tikhonova IG, Neumann S, et al: Identification of residues important for agonist recognition and activation in GPR40. J Biol Chem 282: 29248-29255, 2007.

41. Lu SY, Jiang YJ, Zou JW, et al: Insight into analysis of interactions of GW9508 to wild-type and H86F and H137F GPR40: a combined QM/MM study and pharmacophore modeling. J Mol Graph Model 29: 818-825, 2011.

42. Ogawa T, Hirose H, Miyashita K, et al: GPR40 gene Arg211His polymorphism may contribute to the variation of insulin secretory capacity in Japanese men. Metabolism 54: 296-299, 2005.

43. Vettor R, Granzotto M, De Stefani D, et al: Loss-of-function mutation of the GPR40 gene associates with abnormal stimulated insulin secretion by acting on intracellular calcium mobilization. J Clin Endocrinol Metab 93: 3541-3550, 2008.

44. Briscoe CP, Tadayyon M, Andrews JL, et al: The orphan $\mathrm{G}$ protein-coupled receptor GPR40 is activated by medium and long chain fatty acids. J Biol Chem 278: 11303-11311, 2003.

45. Itoh Y, Kawamata Y, Harada M, et al: Free fatty acids regulate insulin secretion from pancreatic beta cells through GPR40. Nature 422: 173-176, 2003.

46. Kotarsky K, Nilsson NE, Flodgren E, et al: A human cell surface receptor activated by free fatty acids and thiazolidinedione drugs. Biochem Biophys Res Commun 301: 406-410, 2003.

47. Yang M, Chisholm JW, Soelaiman S and Shryock JC: Sulfonylureas uncouple glucose-dependence for GPR40mediated enhancement of insulin secretion from INS-1E cells. Mol Cell Endocrinol 315: 308-313, 2010.

48. Yazaki R, Kumagai N and Shibasaki M: Enantioselective synthesis of a GPR40 agonist AMG 837 via catalytic asymmetric conjugate addition of terminal alkyne to $\alpha, \beta$-unsaturated thioamide. Org Lett 13: 952-955, 2011.

49. Yazaki R, Kumagai $\mathrm{N}$ and Shibasaki M: Cooperative activation of alkyne and thioamide functionalities; direct catalytic asymmetric conjugate addition of terminal alkynes to $\alpha, \beta$-unsaturated thioamides. Chem Asian J 6: 1778-1790, 2011.

50. Walsh SP, Severino A, Zhou C, et al: 3-Substituted 3-(4-aryloxyaryl)-propanoic acids as GPR40 agonists. Bioorg Med Chem Lett 21: 3390-3394, 2011.

51. Zhang X, Yan G, Li Y, et al: DC260126, a small-molecule antagonist of GPR40, improves insulin tolerance but not glucose tolerance in obese Zucker rats. Biomed Pharmacother 64: 647-651, 2010.

52. Hu H, He LY, Gong Z, et al: A novel class of antagonists for the FFAs receptor GPR40. Biochem Biophys Res Commun 390: 557-563, 2009. 
53. Wu J, Sun P, Zhang X, et al: Inhibition of GPR40 protects MIN6 $\beta$ cells from palmitate-induced ER stress and apoptosis. J Cell Biochem 113: 1152-1158, 2012.

54. Zhao Y, Song Y, Shen X and Liao J: Feasible synthesis of antagonist of GPR40 by constructing 2-thiouracil ring via acid mediated cyclization. Heterocycles 83: 1145-1151, 2011.

55. Stein DT, Esser V, Stevenson BE, et al: Essentiality of circulating fatty acids for glucose-stimulated insulin secretion in the fasted rat. J Clin Invest 97: 2728-2735, 1996.

56. Tuei VC, Ha JS and Ha CE: Effects of human serum albumin complexed with free fatty acids on cell viability and insulin secretion in the hamster pancreatic $\beta$-cell line HIT-T15. Life Sci 88: 810-818, 2011.

57. Wang $\mathrm{C}$, Tan $\mathrm{H}, \mathrm{Yu} \mathrm{H}$, et al: Impairment of insulin action in non-obese, normal-glucose tolerant, first-degree relatives of Chinese type 2 diabetic patients. Diabetes Res Clin Pract 91: 67-71, 2011.

58. Lan H, Hoos LM, Liu L, et al: Lack of FFAR1/GPR40 does not protect mice from high-fat diet-induced metabolic disease. Diabetes 57: 2999-3006, 2008.

59. Tan CP, Feng Y, Zhou YP, et al: Selective small-molecule agonists of $\mathrm{G}$ protein-coupled receptor 40 promote glucosedependent insulin secretion and reduce blood glucose in mice. Diabetes 57: 2211-2219, 2008.

60. Fujiwara K, Maekawa F and Yada T: Oleic acid interacts with GPR40 to induce $\mathrm{Ca}^{2+}$ signaling in rat islet beta-cells: mediation by PLC and L-type $\mathrm{Ca}^{2+}$ channel and link to insulin release. Am J Physiol Endocrinol Metab 289: E670-E677, 2005.

61. Shapiro H, Shachar S, Sekler I, et al: Role of GPR40 in fatty acid action on the beta cell line INS-1E. Biochem Biophys Res Commun 335: 97-104, 2005.

62. Latour MG, Alquier T, Oseid E, et al: GPR40 in necessary but not sufficient for fatty acid stimulation of insulin secretion in vivo. Diabetes 56: 1087-1094, 2007.

63. Feng DD, Luo Z, Roh SG, et al: Reduction in voltage-gated $\mathrm{K}^{+}$ currents in primary cultured rat pancreatic beta-cells by linoleic acids. Endocrinology 147: 674-682, 2006.

64. Briscoe CP, Peat AJ, McKeown SC, et al: Pharmacological regulation of insulin secretion in MIN6 cells through the fatty acid receptor GPR40: identification of agonist and antagonist small molecules. Br J Pharmacol 148: 619-628, 2006.

65. Mikami S, Kitamura S, Negoro N, et al: Discovery of phenylpropanoic acid derivatives containing polar functionalities as potent and orally bioavailable $\mathrm{G}$ protein-coupled receptor 40 agonists for the treatment of type 2 diabetes. J Med Chem 55: 3756-3776, 2012.

66. Lin DC, Zhang J, Zhuang R, et al: AMG 837: a novel GPR40/ FFA1 agonist that enhances insulin secretion and lowers glucose levels in rodents. PLoS One 6: e27270, 2011.

67. Wu P, Yang L and Shen X: The relationship between GPR40 and lipotoxicity of the pancreatic $\beta$-cells as well as the effect of pioglitazone. Biochem Biophys Res Commun 403: 36-39, 2010.

68. Meidute Abaraviciene S, Lundquist I, Galvanovskis J, et al: Palmitate-induced beta-cell dysfunction is associated with excessive NO production and is reversed by thiazolidinedionemediated inhibition of GPR40 transduction mechanisms. PLoS One 3: e2182, 2008.

69. Singh S, Loke YK and Furberg CD: Thiazolidinediones and heart failure: a teleo-analysis. Diabetes Care 30: 2148-2153, 2007.

70. Mieczkowska A, Basle MF, Chappard D and Mabilleau G: Thiazolidinediones induced osteocyte apoptosis by a $\mathrm{G}$ proteincoupled receptor 40-dependent mechanism. J Biol Chem 287: 23517-23526, 2012.

71. Zhou C, Tang C, Chang E, et al: Discovery of 5-aryloxy2,4-thiazolidinediones as potent GPR40 agonists. Bioorg Med Chem Lett 20: 1298-1301, 2010.

72. Yashiro H, Tsujihata Y, Takeuchi K, et al: The effects of TAK-875, a selective G protein-coupled receptor 40/free fatty acid 1 agonist, on insulin and glucagon secretion in isolated rat and human islets. J Pharmacol Exp Ther 340: 483-489, 2012.
73. Tsujihata Y, Ito R, Suzuki M, et al: TAK-875, an orally available $\mathrm{G}$ protein-coupled receptor $40 /$ free fatty acid receptor 1 agonist, enhances glucose-dependent insulin secretion and improves both postprandial and fasting hyperglycemia in type 2 diabetic rats. J Pharmacol Exp Ther 339: 228-237, 2011

74. Negoro N, Sasaki S, Mikami S, et al: Optimization of (2,3-dihydro-1-benzofuran-3-yl)acetic acids: discovery of a non-free fatty acid-like, highly bioavailable $\mathrm{G}$ protein-coupled receptor 40/free fatty acid receptor 1 agonist as a glucosedependent insulinotropic agent. J Med Chem 55: 3960-3974, 2012.

75. Naik H, Vakilynejad M, Wu J, et al: Safety, tolerability, pharmacokinetics, and pharmacodynamic properties of the GPR40 agonist TAK-875: results from a double-blind, placebocontrolled single oral dose rising study in healthy volunteers. J Clin Pharmacol 52: 1007-1016, 2012.

76. Araki T, Hirayama M, Hiroi S and Kaku K: GPR40-induced insulin secretion by the novel agonist TAK-875: first clinical findings in patients with type 2 diabetes. Diabetes Obes Metab 14: 271-278, 2012.

77. Burant CF, Viswanathan P, Marcinak J, et al: TAK-875 versus placebo or glimepiride in type 2 diabetes mellitus: a phase 2 , randomised, double-blind, placebo-controlled trial. Lancet 379: 1403-1411, 2012.

78. Xie W, Zhao Y and Zhang Y: Traditional chinese medicines in treatment of patients with type 2 diabetes mellitus. Evid Based Complement Alternat Med 2011: 726723, 2011.

79. Chao M, Zou D, Zhang Y, et al: Improving insulin resistance with traditional Chinese medicine in type 2 diabetic patients. Endocrine 36: 268-274, 2009.

80. Chen DS, Ke B, Huang YJ, et al: Effects of the modified linggui zhugan decoction (see text) combined with short-term very low calorie diets on glycemic control in newly diagnosed type 2 diabetics. J Tradit Chin Med 31: 185-188, 2011.

81. Cicero AF and Tartagni E: Antidiabetic properties of berberine: from cellular pharmacology to clinical effects. Hosp Pract (Minneap) 40: 56-63, 2012

82. Lou T, Zhang Z, Xi Z, et al: Berberine inhibits inflammatory response and ameliorates insulin resistance in hepatocytes. Inflammation 34: 659-667, 2011.

83. Gao N, Zhao TY and Li XJ: The protective effect of berberine on $\beta$-cell lipoapoptosis. J Endocrinol Invest 34: 124-130, 2011.

84. Ko BS, Choi SB, Park SK, et al: Insulin sensitizing and insulinotropic action of berberine from Cortidis rhizoma. Biol Pharm Bull 28: 1431-1437, 2005.

85. Rayasam GV, Tulasi VK, Sundaram S, et al: Identification of berberine as a novel agonist of fatty acid receptor GPR40. Phytother Res 24: 1260-1263, 2010.

86. Park SM, Hong SM, Sung SR, et al: Extracts of Rehmanniae radix, Ginseng radix and Scutellariae radix improve glucosestimulated insulin secretion and beta-cell proliferation through IRS2 induction. Genes Nutr 2: 347-351, 2008.

87. Zhang Y and Liu D: Flavonol kaempferol improves chronic hyperglycemia-impaired pancreatic beta-cell viability and insulin secretory function. Eur J Pharmacol 670: 325-332, 2011.

88. Edfalk S, Steneberg P and Edlund H: Gpr40 is expressed in enteroendocrine cells and mediates free fatty acid stimulation of incretin secretion. Diabetes 57: 2280-2287, 2008.

89. Kruska N and Reiser G: Phytanic acid and pristanic acid, branched-chain fatty acids associated with Refsum disease and other inherited peroxisomal disorders, mediate intracellular $\mathrm{Ca}^{2+}$ signaling through activation of free fatty acid receptor GPR40. Neurobiol Dis 43: 465-472, 2011.

90. Nakamoto K, Nishinaka T, Matsumoto K, et al: Involvement of the long-chain fatty acid receptor GPR40 as a novel pain regulatory system. Brain Res 1432: 74-83, 2012. 